\title{
Comparison of Laser Fluorescence and Digital Radiograph with International Caries Detection and Assessment System in Primary Teeth (In-vivo study)
}

\author{
Rana Kassab \\ Specialist in paedodontics, Faculty of Dentistry, \\ Beirut Arab University, Lebanon \\ Nayer Abo Elsaad \\ Professor, Faculty of Dentistry, Beirut Arab University, Beirut, Lebanon \\ Shiern Badr \\ Assistant Professor, Faculty of Dentistry, \\ Beirut Arab University, Beirut, Lebanon
}

Doi:10.19044/esj.2021.v17n14p24

Submitted: 10 November 2020

Accepted: 05 March 2021

Published: 30 April 2021
Copyright 2021 Author(s)

Under Creative Commons BY-NC-ND

4.0 OPEN ACCESS

Cite As:

Kassab R., Elsaad N.A. \& Badr S. (2021). Comparison of Laser Fluorescence and Digital Radiograph with International Caries Detection and Assessment System in Primary Teeth (Invivo study). European Scientific Journal, ESJ, 17(14), 24.

https://doi.org/10.19044/esj.2021.v17n14p24

\section{Abstract}

Background: There has been an increased incidence of dental caries in children due to recent changes in lifestyle. More sensitive and reproducible diagnostic tools for precise caries detection in children are needed because of the complex occlusal anatomy. Aim: To compare the clinical performance and accuracy of international caries detection and assessment system-II (ICDAS II) versus DIAGNOdent pen and digital bitewing radiograph in the detection of occlusal caries in the primary teeth. Materials and Methods: Fifty children aged 6-11 years were assessed of both gender ( 29 girls and 21 boys) and 377 occlusal surface of primary teeth were examined by visual ICDAS II, DIAGNOdent pen and digital bitewing radiographic examination at D0 (non caries lesions), D1 (lesions limited to enamel) and D2 (lesions limited to dentin) thresholds. Results: Sensitivity at D0 for ICADS II was $14.23 \%$ and 95.95\% for DIAGNOdent pen and $87.85 \%$ for digital bitewing, radiographs while specificity for both ICADS II and bitewing radiographs were $99.23 \%$ 
but $73.85 \%$ for DIAGNOdent pen. At D1, threshold sensitivity of ICADS II and digital bitewing radiographs were higher than DIAGNOdent pen but specificity for bitewing radiographs and DIAGNOdent pen $90.69 \%-87.99 \%$. were highly significant than ICADS II At D2, threshold specificity for all diagnostic methods was almost similar with better sensitivity for ICADS II and digital bitewing radiographs. Conclusion: This study showed that ICDAS II, Diagnodent pen, and bitewing radiography are effective for the detection of occlusal caries for primary molars. Digital bitewing radiography correlated stronger with ICDASII than Diagnodent pen and proved to be the best method to detect occlusal lesions within the dentin in primary molars while Diagnodent pen and bitewing radiography are better for detecting enamel caries lesion. In addition, the clinical performance of three diagnostic methods was insufficient to detect occlusal caries lesions separately. Consequently, it is advisable to use a combination of diagnostic methods, especially in unclear cases, as well as in cases of initial lesions and their monitoring.

Keywords: International Caries Detection and Assessment System II, Diagnodent pen, Digital bitewing radiographs, occlusal caries

\section{Introduction}

There has been an increased incidence of dental caries in children due to recent changes in lifestyle. More sensitive and reproducible diagnostic tools for precise caries detection in children are needed because of the complex occlusal anatomy (Katge F et al., 2016). Diagnosis is both an art and science, combining scientific knowledge and clinical experiences in discovering the signs and symptoms of the caries process (Mohanraj M et al., 2016).

There are different tools for dental diagnosis, which include visual, visuotactile, radiographic, fluorescence-based and electrical conductancebased methods (Bhumireddy et al., 2018). Visual inspection is useful only in the clearest stages of occlusal caries. A new evidence-based optical standard for the detection of dental caries was developed in 2002 to relate the clinical condition of the teeth to their histopathological condition, called the International Dental Caries Discovery and Assessment System (ICDAS). In 2005, an amendment was applied and the ICDAS-II standards were created. ICDAS-II provides standardization in data collection it is comparable to studies and has good reproducibility and accuracy in detecting occlusal caries (Tassoker et al., in 2020).

Since early caries detection is not simple, new technologies have been investigated as diagnostic tools to identify and quantify early caries lesions. These methods, the laser fluorescence-based devices include the DIAGNOdent pen. This device uses a simple diode laser that irradiates the tooth at a specific wavelength. The light is absorbed by organic and inorganic 
substances present in the dental tissues, as well as by metabolites from oral bacteria (porphyrins), showing numerical values to differentiate between sound and carious tissues (Kouchaji, 2012). The values range from 0 to 99 on the screen of the device. Higher values indicate more extensive caries lesion (Nokhbatolfoghahaie et al., 2013).

Recently, there has been an increasing popularity of digital radiographs compared to conventional radiographs because of the time-consuming processing of conventional radiographs, the decreased patient exposure to ionizing radiation in digital radiography, and the possibility of changing the contrast and density with the digital radiographs (Dehghani et al., 2017).

It is a commonly used method for caries detection as some clinicians believe that even in an ideal clinical situation with good light and clean and dry teeth, clinical examinations conducted without adjunctive radiography have shown to underestimate the actual caries lesion level. However, it has some limitations (Abdelaziz et al., 2018). The limitation of radiographic examination lies in being inaccurate in determining the extension of the carious lesions and it is only possible to observe the lesion when the demineralization has already affected at least $30 \%$ to $40 \%$ of the enamel, causing irreversible mineral loss (Bader, Shugars and Bonito 2001). Moreover, the radiographic examination does not enable the detection of caries activity (Loiola et al., 2012).

\section{Aim of the Study:}

To compare the clinical performance and accuracy of international caries detection and assessment system- II (ICDAS II) versus DIAGNOdent pen and digital bitewing radiography in the detection of occlusal caries in the primary teeth.

\section{Materials and Methods:}

This study was an in vivo study. All participants recruited from the diagnosis clinic, all clinical and radiographic procedures were conducted in dental clinics at the faculty of dentistry, Beirut Arab University. A total number of 377 primary teeth in a minimum of 50 children will be included in this study according to the sample size calculation through free online sample size calculator raosoft with a margin of error 5\% and confidence level $95 \%$. Both genders were selected according to the following inclusion and exclusion criteria.

\section{Inclusion Criteria:}

The participants enrolled in this study showed the following criteria:

$>$ Children aged 6-11years old. 
$>$ Children have at least two primary molars that require diagnostic radiographs.

$>$ All children should be free of any medical conditions

\section{Exclusion Criteria:}

Children were excluded if they showed the following criteria:

$>$ Uncooperative behavior.

$>$ Children with special health care needs.

$>$ Children with developmental anomalies of teeth.

$>$ Children of parents who refused to sign the consent agreement.

\section{Ethical Approval}

Ethical approval from the Beirut Arab University Institutional Review Board (IRB-BAU) was obtained before conducting the study (IRB code: 2019H-0072-D-M-0357). Moreover, the study protocol was approved from ethical and scientific committee at BAU before initiation of the study. The objectives, risk, benefits of the study were explained to parents/guardians, and a signed informed consent was obtained before inclusion in the study.

\section{Intra Examiner Reliability}

The operator was calibrated for using DIAGNOdent pen, ICADS, and Bitewing Radiographic Examination for accurate diagnosis. Each occlusal surface was measured three times by described procedure, and the average of these three measurements was considered as a definite value. After achieving a consistent reproducibility verified by the senior investigator the examiner has carried out the study.Kappa test was calculated to ensure an appropriate level of agreement with gold standard examiner and reliability (Kappa=91).

\section{Methodology}

1. Visual Examination (ICADS II): All visual examination will be conducted under standard conditions with patients positioned in a dental chair, a professional dental light with a plain dental mirror and air/water spray for drying teeth during 5 seconds (AIjehaniet al.,2007). After that, visual ICDAS II scorings will be recorded according to ICADS II criteria (Table1) (Fig.1).

2. Laser Fluorescence Examination (DIAGNOdent Pen): Scanning with the laser fluorescence system will be performed following manufacturer instructions. The DIAGNOdent pen readings will be recorded according to the scale. (Bhumireddy et al., 2018)(table 2)(Fig.2).

3. Radiographic Examination (Digital Bitewing Radiographs): For radiographic examination, digital bitewing radiographs with a digital 
sensor holder will be used. The examination and scoring will be done according to the radiographic criteria (Dunkley et al., 2007) (Table 3) (Fig.3).

\section{Validation Method}

The validation of the findings (gold standard) was determined by fissure eradication as a part of restorative procedure. However, not all fissures could be legitimized, as this is an invasive method. In addition, the examiners used the dentin hardness criterion to distinguish the carious and healthy dentin. Consequently, for ethical reasons, opening of the cavities occurred only in cases when examiners agreed to the presence of dentin caries. The caries lesion was removed until hard dentin was found. In addition, the examiners used the dentin hardness criterion to distinguish the carious and healthy dentin.

Table 1: Description of International Caries Detection and Assessment System II visual criteria (ICADS II) (Bhumireddy et al., 2018)

\begin{tabular}{|l|l|}
\hline Code & \multicolumn{1}{|c|}{ Clinical criteria description } \\
\hline $\mathbf{0}$ & Sound tooth surface: no evidence of caries after prolonged air drying (5 s) \\
\hline $\mathbf{1}$ & $\begin{array}{l}\text { First visual change in enamel: opacity or discoloration (white or brown) is } \\
\text { visible at the entrance to the pit or fissure after prolonged air drying, which is } \\
\text { not or hardly seen on a wet surface. }\end{array}$ \\
\hline $\mathbf{2}$ & $\begin{array}{l}\text { Distinct visual change in enamel: opacity or discoloration distinctly visible at } \\
\text { the entrance to the pit and fissure when wet, the lesion must still be visible when } \\
\text { dry. }\end{array}$ \\
\hline $\mathbf{3}$ & $\begin{array}{l}\text { Localized enamel breakdown due to caries with no visible dentin or underlying } \\
\text { shadow: opacity or discoloration wider than the natural fissure fossa when wet } \\
\text { and after prolonged air drying. }\end{array}$ \\
\hline $\mathbf{4}$ & $\begin{array}{l}\text { Underlying dark shadow from dentin localized enamel breakdown. } \\
\text { Distinct cavity with visible dentin: visual evidence of demineralization and } \\
\text { dentin exposed. }\end{array}$ \\
\hline $\mathbf{5}$ & $\begin{array}{l}\text { Extensive distinct cavity with visible dentin and more than half of the surface } \\
\text { involved. }\end{array}$ \\
\hline
\end{tabular}


European Scientific Journal, ESJ

April 2021 edition Vol.17, No.14

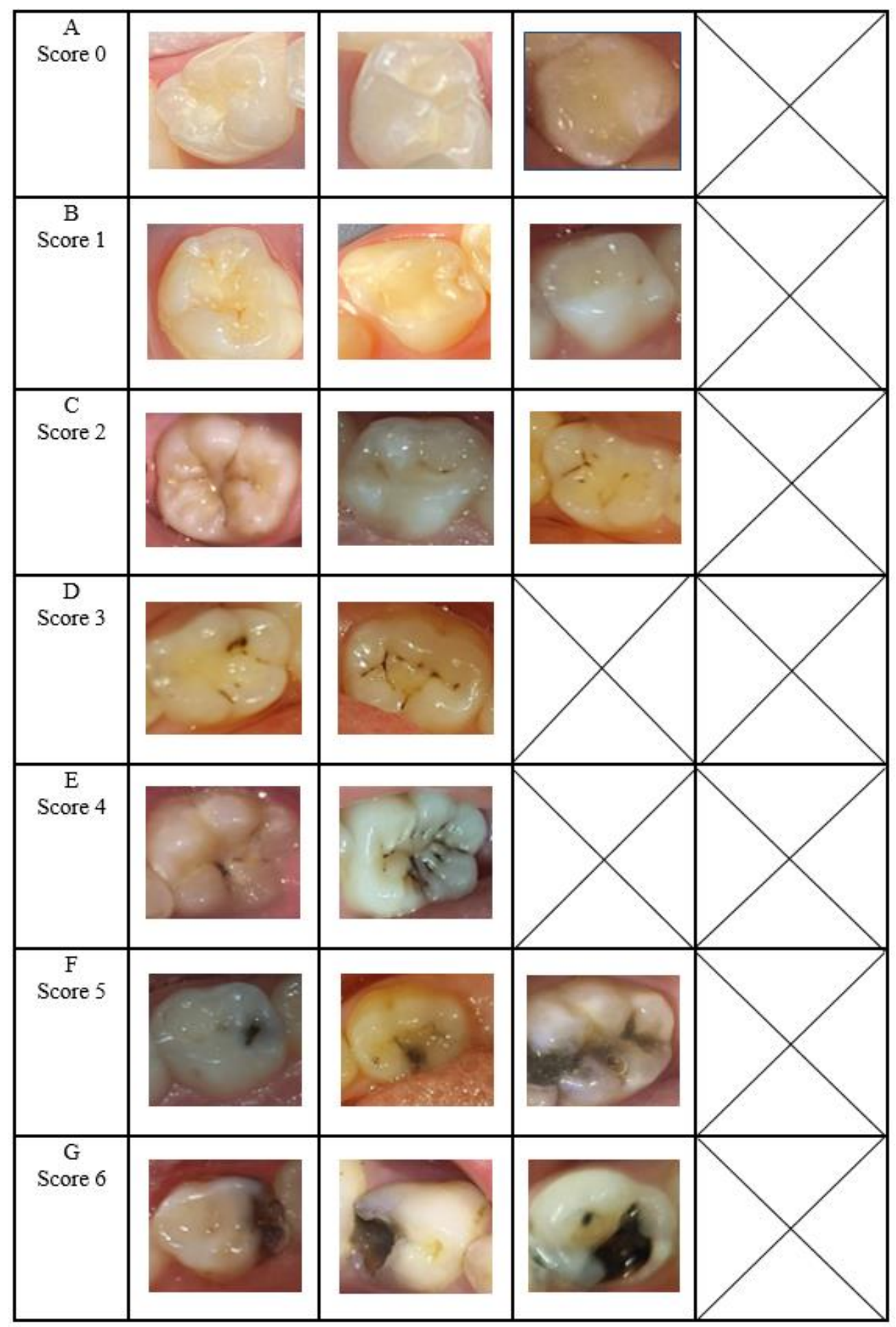

Figure 1: ICADS II criteria for primary teeth in upper and lower quadrant 
Table 2: Scale of DIAGNOdent Pen scores

\begin{tabular}{|l|c|}
\hline \multicolumn{1}{|c|}{ Display value } & Clinical situation \\
\hline $\mathbf{0 - 1 3}$ & Healthy tooth. \\
\hline $\mathbf{1 4 - 2 0}$ & Enamel caries \\
\hline $\mathbf{2 1 - 2 9}$ & Deep enamel caries \\
\hline $\mathbf{3 0}$ & Dentin caries \\
\hline
\end{tabular}

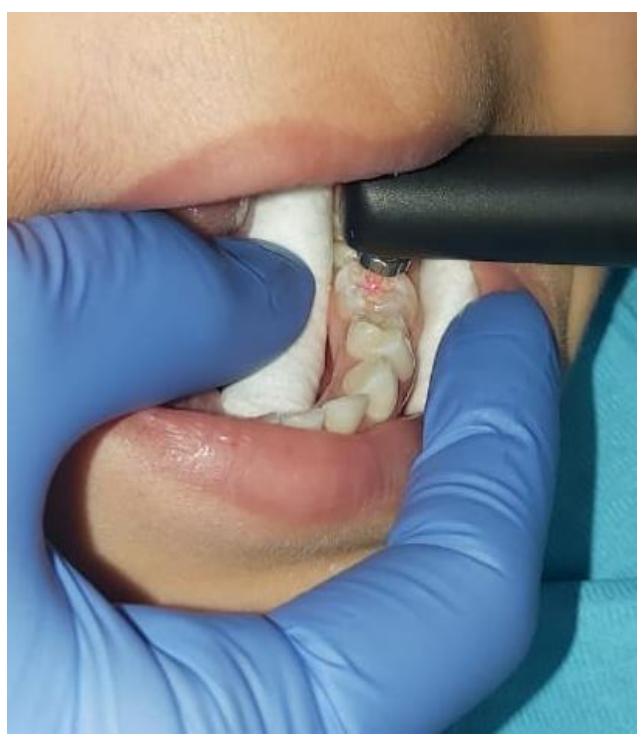

Figure 2: Isolation and application DIAGNOdent pen for lower left primary molars

Table 3: Radiographic Examination scores

\begin{tabular}{|l|l|}
\hline Score & \multicolumn{1}{|c|}{ Radiographic criteria description } \\
\hline $\mathbf{0}$ & No radiolucency. \\
\hline $\mathbf{1}$ & Radiolucency confined to the enamel. \\
\hline $\mathbf{2}$ & Radiolucency in the outer third of the dentine. \\
\hline $\mathbf{3}$ & Radiolucency in the middle third of the dentine. \\
\hline $\mathbf{4}$ & Radiolucency is reaching the pulpal third of the dentine. \\
\hline
\end{tabular}



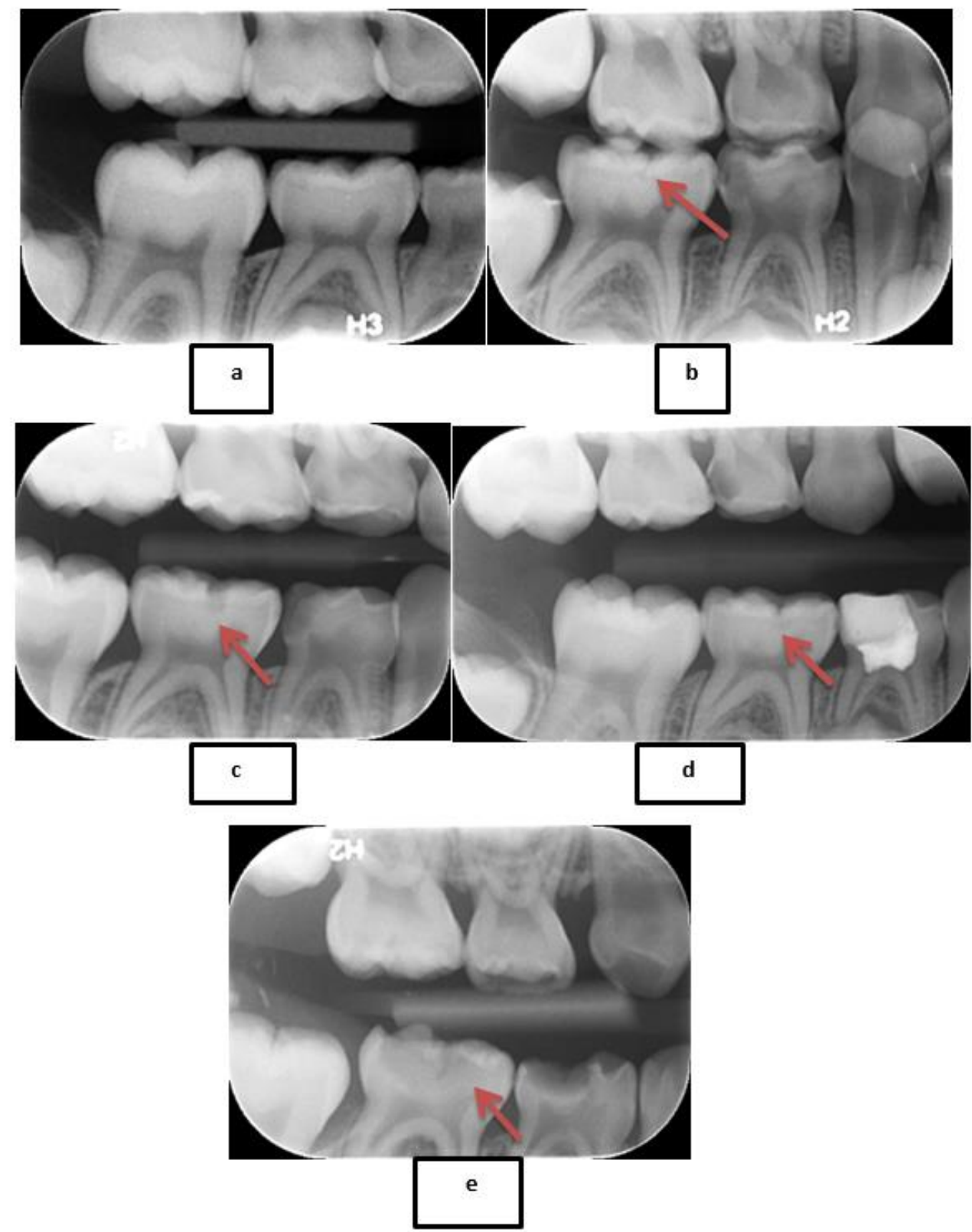

Figure 3: (a, b, c,d and e) Scoring of Digital Bitewing Radiograph (red arrows) in different quadrants of primary teeth a: represent score $0, \mathrm{~b}$ : represent score $1, \mathrm{c}$ : represent score $2, \mathrm{~d}$ : represent score 3 and e : represent score 4

\section{Statistical Analysis:}

All analyses were carried out using statistical software SPSS statistics version 24 (IBM, Armonk, New York), and the level of significance was P < 0.05. Diagnostic performance of each method (ICDAS and Diagnodent pen, 
and Bitewing radiography methods) was evaluated using parameters such as sensitivity, specificity, negative predictive value, positive predictive value, and accuracy at three different thresholds, D0 (No Carries), D1 (Enamel) and D2 (dentine). Accuracy was defined as the percentage of correct diagnosis in all samples (sound and decayed surfaces). For ICDAS and radiographic methods, Score 1 represented the cut-off point for all lesions (D1 threshold) and Score 2 for lesions in dentine (D2 threshold). The $\chi 2$ test was employed to compare sensitivity, specificity, and accuracy values of the different methods. The level of significance for the $\chi 2$ test was $\mathrm{P}<0.05$.

\section{Results}

Fifty children (29 girls and 21 boys) aged 6-11 years old and 377 occlusal surfaces of the primary molar (maxilla and mandible) were enrolled; none declined to participate. At D1, threshold sensitivity of ICADS II and digital bitewing radiographs were statistically higher than DIAGNOdent pen but specificity for bitewing radiographs and DIAGNOdent pen 90.69\% $87.99 \%$ were statistically highly significant than ICADS II (Table4 \& Table5). The accuracy of bitewing radiograph and DIAGNOdent pen was statistically $91.25 \%-82.76 \%$ higher than ICDAS II $38.58 \%$. At D2, threshold specificity for all diagnostic methods was almost similar with better sensitivity for ICADS II and digital bitewing radiographs. Bitewing radiographic accuracy was the best to detect the dentinal caries by $99 \%$ followed by ICDAS II and Diagnodent pen $92 \%$ - 89\% (Table 6 \& Table7).

Table 4: Diagnostic accuracy at D1 threshold (Enamel) for ICADS II, Diagnodent Pen, and Bitewing Radiography:

\begin{tabular}{|c|c|c|c|}
\hline Measurements & ICADS & DP & $\mathbf{B R}$ \\
\hline True positive & 40 & 19 & 42 \\
\hline False negative & 4 & 25 & 2 \\
\hline False positive & 230 & 40 & 31 \\
\hline True negative & 107 & 293 & 302 \\
\hline Sensitivity & $90.91 \%$ & $43.18 \%$ & $95.45 \%$ \\
\hline Specificity & $31.75 \%$ & $87.99 \%$ & $90.69 \%$ \\
\hline Positive predictive value (Precision) & $14.81 \%$ & $32.20 \%$ & $57.53 \%$ \\
\hline Negative predictive value & $96.40 \%$ & $92.14 \%$ & $99.34 \%$ \\
\hline
\end{tabular}

Table 5: Test accuracy of all diagnostic methods

\begin{tabular}{ll}
\hline Test & Percentage of Accuracy \\
\hline ICADS & $38.58 \%$ \\
DP & $82.76 \%$ \\
BR & $91.25 \%$ \\
\hline
\end{tabular}


Table 6: Diagnostic accuracy at D2 threshold (Dentin) for ICADS II, Diagnodent Pen, and Bitewing Radiography:

\begin{tabular}{lccc}
\hline \multicolumn{1}{c}{ Measurements } & ICADS & DP & BR \\
\hline True positive & 63 & 46 & 85 \\
False negative & 23 & 40 & 1 \\
False positive & 7 & 1 & 1 \\
True negative & 284 & 290 & 290 \\
Sensitivity & $73.26 \%$ & $53.49 \%$ & $98.84 \%$ \\
Specificity & $97.59 \%$ & $99.66 \%$ & $99.66 \%$ \\
Positive predictive value (Precision) & $90.00 \%$ & $97.87 \%$ & $98.84 \%$ \\
Negative predictive value & $92.51 \%$ & $87.88 \%$ & $99.66 \%$ \\
\hline
\end{tabular}

Table 7: Test accuracy of all diagnostic methods

\begin{tabular}{cc}
\hline Test & Percentage of accuracy \\
\hline ICADS & $92 \%$ \\
DP & $89 \%$ \\
BR & $99 \%$ \\
\hline
\end{tabular}

\section{Discussion}

Dental caries lesions constitute a significant challenge in our daily practice, clinical management of these lesions should emphasize their early detection, and prevention before a restorative approach is applied.

This in-vivo study was initiated to evaluate and gain knowledge about the clinical performance of different caries detection methods suggested to aid the clinical decision-making process. A stronger association and an outstanding specificity were found between ICADII and the bitewing radiographs in earlier comparable studies when the lesion threshold was of dentin, but that was at the expense of low sensitivity. However, the most striking outcome was the strong performance of the bitewing radiographs as it was effective in both non-cavitated and cavitated thresholds.

The true validation of caries detection methods measuring the presence/absence and extent of caries in the in vivo studies is justified by clinical examination or operative evaluation. The validation method used in true vitro studies histological examination is considered as gold standard (Castilho et al., 2016). The validation of the collected data was performed via cavity opening. For ethical reasons, operative treatment was performed when the results of two diagnostic methods were in favour of the presence of lesion approximately the enamel-dentinal border, or dentinal caries.

A greater understanding of caries lesions has led to a paradigm shift in its management. Intervention has traditionally been the initial course of treatment, but recent evidence indicates that prevention is a better first step. A system that can support this new paradigm in dental caries management has garnered significant interest. The International Caries Detection and 
Assessment System (ICDAS) is evidence-based tools for assessing the severity of caries (Zandona \& Epure, 2018).

Mortensen et al., in 2018, evaluated the performance of bitewing radiographs, the DIAGNOdent pen, and ICDAS. The result of this study is in agreement with our results that the digital bitewing correlated in a stronger manner with ICDASII than with the DIAGNOdent pen and proved to be the best method to detect occlusal lesions within the dentin.

The digital radiographic method has been introduced as an adjuvant tool for caries lesion detection with advantages. However, in pediatric dentistry, this method has not been fully employed for caries detection. The consciousness and the experience of "hidden caries," which is a caries lesion seen in dentine by radiographic examination and clinically presents as sound or demineralized occlusal enamel, have promoted the clinician's attention to the value of radiographic examination for occlusal and proximal surfaces (Diniz et al.,2010). Many studies have concluded that the use of laser fluorescence can improve the detection of carious lesions; particularly at an early stage because of these hidden deep lesions are major challenges for visual inspection (Walsh, 2018). This agreed with our results that the accuracy and clinical performance of DIAGNOdent pen and digital bitewing radiographs was better than ICDASII.

A systematic review has concluded that radiographs are highly accurate for the detection of cavitated approximal lesions, but rare or no studies could be identified that reported on occlusal lesion (Schwendicke, Tzschoppe, and Paris (2015). Also, the available literature review about occlusal caries lesions detection in primary teeth are limited because most of the diagnostic methods were investigated in vitro, not in vivo, which is critical for generalized research findings. For this reason, the present study aimed to determine the clinical performance of ICADII versus the DIAGNOdent pen and bitewing digital radiography to discover the occlusal caries in the primary molars. Aside from revealing the lesion, knowing the lesion extending into the dental tissue is crucial to the choice of restorative materials and the success of the treatment being performed.

Nuvvula et al., in 2016 stated that it is very important to perform digital radiograph in vivo studies to know the accuracy of diagnostic methods in detection of carious lesions. Previous studies looked at the effect of image enhancement on diagnostic accuracy and found out that some enhancement procedures resulted in higher accuracy. On the other hand, others revealed there is no effect on diagnostic accuracy. The dilemma continues and there is insufficient evidence to support the accuracy of digital radiography. Based on this controversy, we decided to work on bitewing digital images in the present study. 
Schaefer et al., in 2018 compared the diagnostic outcomes of visual inspection, digital bitewing radiography for occlusal caries detection and assessment of posterior teeth. They have concluded that, the bitewing radiography had no significant benefit to analyze occlusal surfaces. In contrast, our findings confirmed that the bitewing radiography significantly high effective in detection occlusal surfaces. However, this finding depends on the characteristics of the study population, and different results might be possible in different samples with divergent parameters such as age, caries experience and risk, and socio-economic status.

There are several studies evaluating the effectiveness and accuracy of the DIAGNOden pen in the detection of occlusal caries its performance was in primary teeth better than traditional methods such as visual inspection and X-ray examination. Additionally, some other studies reported that these fluorescence-based devices should be used as additions to traditional methods in clinical practice. For example, Neuhaus et al., in 2011 compared the performance DIAGNOden pen with ICDASII and radiographic examination on occlusal surfaces of primary teeth. They found that the DIAGNOden pen it is used as an aid with ICDASII for better diagnosis (Akgul et al., 2018). This result is similar to our findings that both diagnostic methods will give an examination that is more accurate if they used together.

Sürme et al., in 2020 evaluated the performance of the International Caries Detection and Assessment System (ICDAS)-II and DIAGNOdent pen in detecting occlusal carious lesions in an in- vitro. The diagnostic methods were evaluated at D1, D2, and D3 thresholds and they concluded that the DIAGNOdent Pen and (ICDAS)-II methods might be effective in detecting hidden occlusal caries in both primary and permanent teeth. These results are in agreement with the outcomes of the current study that both methods have proven their effectiveness in occlusal surface of primary molars.

While Hassan et al., in 2019, evaluated the clinical sensitivity and specificity of the DIAGNOdent pen and the ICDAS II in the detection of initial occlusal carious lesions in 50 children. One occlusal surface of each tooth with carious lesions ranging from 0 to 3 was as a gold standard. The results showed that both methods showed a high correlation in early caries detection. However, in difficult diagnoses, the DIAGNOdent pen provides additional sensitivity than ICDAS II. This result agreed with our results that there are a high correlation in caries detection and clinical validation for both methods. The sensitivity of DIAGNOdent pen in present study was $95.95 \%$ while only $14.23 \%$ for ICDAS II.

Conducting adequately sizes randomized control trials to study the effectiveness of all caries lesions detection methods and devices for primary teeth targeting both high and low-risk population to help in updating existing strategies. 


\section{Conclusion}

This study showed that ICDAS II, Diagnodent pen, and bitewing radiography are effective for the detection of occlusal caries for primary molars. Digital bitewing radiography correlated stronger with ICDASII than Diagnodent pen and proved to be the best method to detect occlusal lesions within the dentin in primary molars while Diagnodent pen and bitewing radiography are better for detecting enamel caries lesion. In addition, the clinical performance of three diagnostic methods was insufficient to detect occlusal caries lesions separately. Consequently, it is advisable to use a combination of diagnostic methods, especially in unclear cases, as well as in cases of initial lesions and their monitoring.

\section{References:}

1. Andersen JH, Jenssen H, Sandvik K, Gutteberg TJ. Anti-HSV activity of lactoferrin and lactoferricin is dependent on the presence of heparan sulphate at the cell surface. J Med Virol. 2004 Oct;74(2):262-71.

2. Baveye S, Elass E, Mazurier J, Spik G, Legrand D. Lactoferrin: a multifunctional glycoprotein involved in the modulation of the inflammatory process. Clin Chem Lab Med. 1999 Mar;37(3):281-6.

3. Begbie M, Notley C, Tinlin S, Sawyer L, Lillicrap D. The Factor VIII acute phase response requires the participation of NFkappaB and C/EBP. Thromb Haemost. 2000 Aug;84(2):216-22.

4. Belting M. Heparan sulfate proteoglycan as a plasma membrane carrier. Trends Biochem Sci. 2003 Mar;28(3):145-51.

5. Chan JF, Yuan S, Kok KH, To KK, Chu H, Yang J, Xing F, Liu J, Yip CC, Poon RW, Tsoi HW, Lo SK, Chan KH, Poon VK, Chan WM, Ip JD, Cai JP, Cheng VC, Chen H, Hui CK, Yuen KY. A familial cluster of pneumonia associated with the 2019 novel coronavirus indicating person-to-person transmission: a study of a family cluster. Lancet. 2020 Feb 15;395(10223):514-523.

6. Chen L, Liu HG, Liu W, Liu J, Liu K, Shang J, Deng Y, Wei S. [Analysis of clinical features of 29 patients with 2019 novel coronavirus pneumonia]. Zhonghua Jie He He Hu Xi Za Zhi. 2020 Mar 12;43(3):203-208. Chinese.

7. Chen T, Wu D, Chen H, Yan W, Yang D, Chen G, Ma K, Xu D, Yu H, Wang H, Wang T, Guo W, Chen J, Ding C, Zhang X, Huang J, Han M, Li S, Luo X, Zhao J, Ning Q. Clinical characteristics of 113 deceased patients with coronavirus disease 2019: retrospective study. BMJ. 2020 Mar 26;368:m1091.

8. Clausen TM, Sandoval DR, Spliid CB, Pihl J, Perrett HR, Painter CD, Narayanan A, Majowicz SA, Kwong EM, McVicar RN, Thacker BE, Glass CA, Yang Z, Torres JL, Golden GJ, Bartels PL, Porell RN, 
Garretson AF, Laubach L, Feldman J, Yin X, Pu Y, Hauser BM, Caradonna TM, Kellman BP, Martino C, Gordts PLSM, Chanda SK, Schmidt AG, Godula K, Leibel SL, Jose J, Corbett KD, Ward AB, Carlin AF, Esko JD. SARS-CoV-2 Infection Depends on Cellular Heparan Sulfate and ACE2. Cell. 2020 Nov 12;183(4):1043-1057.e15.

9. Drakesmith H, Prentice A. Viral infection and iron metabolism. Nat Rev Microbiol. 2008 Jul;6(7):541-52.

10. Elass-Rochard E, Legrand D, Salmon V, Roseanu A, Trif M, Tobias PS, Mazurier J, Spik G. Lactoferrin inhibits the endotoxin interaction with CD14 by competition with the lipopolysaccharide-binding protein. Infect Immun. $1998 \mathrm{Feb}$;66(2):486-91.

11. Frioni A, Conte MP, Cutone A, Longhi C, Musci G, di Patti MC, Natalizi T, Marazzato M, Lepanto MS, Puddu P, Paesano R, Valenti $\mathrm{P}$, Berlutti F. Lactoferrin differently modulates the inflammatory response in epithelial models mimicking human inflammatory and infectious diseases. Biometals. 2014 Oct;27(5):843-56.

12. Ganz T. Hepcidin and iron regulation, 10 years later. Blood. 2011 Apr 28;117(17):4425-33.

13. Guan WJ, Ni ZY, Hu Y, Liang WH, Ou CQ, He JX, Liu L, Shan H, Lei CL, Hui DSC, Du B, Li LJ, Zeng G, Yuen KY, Chen RC, Tang CL, Wang T, Chen PY, Xiang J, Li SY, Wang JL, Liang ZJ, Peng YX, Wei L, Liu Y, Hu YH, Peng P, Wang JM, Liu JY, Chen Z, Li G, Zheng ZJ, Qiu SQ, Luo J, Ye CJ, Zhu SY, Zhong NS; China Medical Treatment Expert Group for Covid-19. Clinical Characteristics of Coronavirus Disease 2019 in China. N Engl J Med. 2020 Apr 30;382(18):1708-1720.

14. Hamming I, Timens W, Bulthuis ML, Lely AT, Navis G, van Goor H. Tissue distribution of ACE2 protein, the functional receptor for SARS coronavirus. A first step in understanding SARS pathogenesis. J Pathol. 2004 Jun;203(2):631-7.

15. Hoffmann M, Kleine-Weber H, Schroeder S, Krüger N, Herrler T, Erichsen S, Schiergens TS, Herrler G, Wu NH, Nitsche A, Müller MA, Drosten C, Pöhlmann S. SARS-CoV-2 cell entry depends on ACE2 and TMPRSS 2 and is blocked by a clinically proven protease inhibitor. Cell. 2020 Apr 16;181(2):271-280.e8.

16. Huang C, Wang Y, Li X, Ren L, Zhao J, Hu Y, Zhang L, Fan G, Xu J, Gu X, Cheng Z, Yu T, Xia J, Wei Y, Wu W, Xie X, Yin W, Li H, Liu M, Xiao Y, Gao H, Guo L, Xie J, Wang G, Jiang R, Gao Z, Jin Q, Wang J, Cao B. Clinical features of patients infected with 2019 novel coronavirus in Wuhan, China. Lancet. 2020 Feb 15;395(10223):497506. 
17. Hunt B, Retter, A., McClintock, C. Practical guidance for the prevention of thrombosis and management of coagulopathy and disseminated intravascular coagulation of patients infected with COVID-19. British Society for Haematology. 2020.

18. Idell S, Koenig KB, Fair DS, Martin TR, McLarty J, Maunder RJ. Serial abnormalities of fibrin turnover in evolving adult respiratory distress syndrome. Am J Physiol. 1991;261:L240-8.

19. Iqbal T, Stein J, Sharma N, Kulnigg-Dabsch S, Vel S, Gasche C. Clinical significance of $\mathrm{C}$-reactive protein levels in predicting responsiveness to iron therapy in patients with inflammatory bowel disease and iron deficiency anemia. Dig Dis Sci. 2015 May;60(5):1375-81.

20. Kapoor S, Opneja A, Nayak L. The role of neutrophils in thrombosis. Thromb Res. 2018;170:87-96.

21. Kell DB, Pretorius E. No effects without causes: the Iron Dysregulation and Dormant Microbes hypothesis for chronic, inflammatory diseases. Biol Rev Camb Philos Soc. 2018 Aug;93(3):1518-1557.

22. Kyrle PA, Minar E, Hirschl M, Bialonczyk C, Stain M, Schneider B, Weltermann A, Speiser W, Lechner K, Eichinger S. High plasma levels of factor VIII and the risk of recurrent venous thromboembolism. N Engl J Med. 2000 Aug 17;343(7):457-62.

23. Lang J, Yang N, Deng J, Liu K, Yang P, Zhang G, Jiang C. Inhibition of SARS pseudovirus cell entry by lactoferrin binding to heparan sulfate proteoglycans. PLoS One. 2011;6(8):e23710.

24. Legrand D. Overview of Lactoferrin as a Natural Immune Modulator. J Pediatr. 2016 Jun;173 Suppl:S10-5.

25. Levay PF, Viljoen M. Lactoferrin: a general review. Haematologica. 1995 May-Jun;80(3):252-67.

26. Luxembourg B, Schmitt J, Humpich M, Glowatzki M, Seifried E, Lindhoff-Last E. Intrinsic clotting factors in dependency of age, sex, body mass index, and oral contraceptives: definition and risk of elevated clotting factor levels. Blood Coagul Fibrinolysis. 2009 Oct;20(7):524-34.

27. Motta I, Migone De Amicis M, Pinto VM, Balocco M, Longo F, Bonetti F, Gianesin B, Graziadei G, Cappellini MD, De Franceschi L, Piga A, Forni GL. SARS-CoV-2 infection in beta thalassemia: Preliminary data from the Italian experience. Am J Hematol. 2020 Aug;95(8):E198-E199.

28. Ng TB, Cheung RC, Wong JH, Wang Y, Ip DT, Wan DC, Xia J. Antiviral activities of whey proteins. Appl Microbiol Biotechnol. 2015 Sep;99(17):6997-7008. 
29. Panigada M, Bottino N, Tagliabue P, Grasselli G, Novembrino C, Chantarangkul V, Pesenti A, Peyvandi F, Tripodi A. Hypercoagulability of COVID-19 patients in intensive care unit: A report of thromboelastography findings and other parameters of hemostasis. J Thromb Haemost. 2020 Jul;18(7):1738-1742.

30. Pelsers MM, Moravat A, Alexander GJM, Hermens WT, Trull AK, Glatz JFC. Liver fatty acid-binding protein as a sensitive serum marker of acute hepato- cellular damage in liver transplant recipients. Clin Chem. 2002; 48:2055-7.

31. Redwan EM, Uversky VN, El-Fakharany EM, Al-Mehdar H. Potential lactoferrin activity against pathogenic viruses. C R Biol. 2014 Oct;337(10):581-95.

32. Shi S, Qin M, Shen B, Cai Y, Liu T, Yang F, Gong W, Liu X, Liang J, Zhao Q, Huang H, Yang B, Huang C. Association of Cardiac Injury With Mortality in Hospitalized Patients With COVID-19 in Wuhan, China. JAMA Cardiol. 2020 Jul 1;5(7):802-810.

33. Shovlin CL, Sulaiman NL, Govani FS, Jackson JE, Begbie ME. Elevated factor VIII in hereditary haemorrhagic telangiectasia (HHT): association with venous thromboembolism. Thromb Haemost. 2007 Nov;98(5):1031-9.

34. Tang N, Bai H, Chen X, Gong J, Li D, Sun Z. Anticoagulant treatment is associated with decreased mortality in severe coronavirus disease 2019 patients with coagulopathy. J Thromb Haemost. 2020 May;18(5):1094-1099.

35. Teraguchi S, Wakabayashi H, Kuwata H, Yamauchi K, Tamura Y. Protection against infections by oral lactoferrin: evaluation in animal models. Biometals. 2004 Jun;17(3):231-4.

36. Thachil J, Tang N, Gando S, Falanga A, Levi M, Clark C, Iba T, Cattaneo M. Type and dose of heparin in Covid-19: Reply. J Thromb Haemost. 2020 Aug;18(8):2063-2064.

37. Theurl I, Aigner E, Theurl M, Nairz M, Seifert M, Schroll A, Sonnweber T, Eberwein L, Witcher DR, Murphy AT, Wroblewski VJ, Wurz E, Datz C, Weiss G. Regulation of iron homeostasis in anemia of chronic disease and iron deficiency anemia: diagnostic and therapeutic implications. Blood. 2009 May 21;113(21):5277-86.

38. Trend S, Strunk T, Lloyd ML, Kok CH, Metcalfe J, Geddes DT, Lai CT, Richmond P, Doherty DA, Simmer K, Currie A. Levels of innate immune factors in preterm and term mothers' breast milk during the 1st month postpartum. Br J Nutr. 2016 Apr 14;115(7):1178-93.

39. Valenti P, Frioni A, Rossi A, Ranucci S, De Fino I, Cutone A, Rosa L, Bragonzi A, Berlutti F. Aerosolized bovine lactoferrin reduces neutrophils and pro-inflammatory cytokines in mouse models of 
Pseudomonas aeruginosa lung infections. Biochem Cell Biol. 2017 Feb;95(1):41-47.

40. Wakabayashi H, Oda H, Yamauchi K, Abe F. Lactoferrin for prevention of common viral infections. J Infect Chemother. 2014 Nov;20(11):666-71.

41. Wang D, Hu B, Hu C, Zhu F, Liu X, Zhang J, Wang B, Xiang H, Cheng Z, Xiong Y, Zhao Y, Li Y, Wang X, Peng Z. Clinical Characteristics of 138 Hospitalized Patients With 2019 Novel Coronavirus-Infected Pneumonia in Wuhan, China. JAMA. 2020 Mar 17;323(11):10611069.

42. Witte DL. Can serum ferritin be effectively interpreted in the presence of the acute-phase response? Clin Chem. 1991 Apr;37(4):484-5.

43. World Health Organization [Available from: https://covid19.who.int/]

44. Wu C, Chen X, Cai Y, Xia J, Zhou X, Xu S, Huang H, Zhang L, Zhou X, Du C, Zhang Y, Song J, Wang S, Chao Y, Yang Z, Xu J, Zhou X, Chen D, Xiong W, Xu L, Zhou F, Jiang J, Bai C, Zheng J, Song Y. Risk factors associated with acute respiratory distress syndrome and death in patients with coronavirus disease 2019 pneumonia in Wuhan, China. JAMA Intern Med. 2020 Jul 1;180(7):934-943.

45. Zhang Q, Chen CZ, Swaroop M, Xu M, Wang L, Lee J, Wang AQ, Pradhan M, Hagen N, Chen L, Shen M, Luo Z, Xu X, Xu Y, Huang W, Zheng W, Ye Y. Heparan sulfate assists SARS-CoV-2 in cell entry and can be targeted by approved drugs in vitro. Cell Discov. 2020 Nov $4 ; 6(1): 80$.

46. Zhang Q, Chen CZ, Swaroop M, Xu M, Wang L, Lee J, Wang AQ, Pradhan M, Hagen N, Chen L, Shen M, Luo Z, Xu X, Xu Y, Huang $\mathrm{W}$, Zheng $\mathrm{W}$, Ye Y. Targeting heparan sulfate proteoglycan-assisted endocytosis as a COVID-19 therapeutic option. bioRxiv [Preprint]. 2020 Jul 14:2020.07.14.202549. 